\title{
Los espacios del poder en el medio rural: torres de alquería en el mundo nazarí
}

\author{
Spaces of power in Nasrid rural milieu: the alquería towers
}

\author{
Adela Fábregas García * \\ Raúl González Arévalo *
}

\begin{abstract}
RESUMEN
Se aborda una revisión del análisis de una de las estructuras materiales que más presencia asumen en el medio rural nazarí: las torres de alquería. Asumida hasta ahora sin más su caracterización como estructuras menores que formarían parte del sistema defensivo nazarí, la nueva propuesta de interpretación que lanzamos pretende entender hasta qué punto estas construcciones son obra de la iniciativa estatal y de sus planes defensivos o de control territorial, o si, por el contrario, estamos ante un reducto de autonomía de gestión de las comunidades campesinas, de las que podría partir el impulso de su construcción y uso, frente a otros espacios de control estatal.
\end{abstract}

Palabras clave: Nazarí, Poder, Crónicas, Alquerías, Torres

\section{INTRODUCCIÓN}

En 2011 tuvo inicio un proyecto de investigación que esperamos que abra una línea de trabajo dedicada de manera amplia al conocimiento de las formas de poder vigentes en el reino nazarí, a sus derivaciones y representaciones locales y a su capacidad para penetrar en los antiguos sistemas de gestión campesina. En ese espacio podría preservarse aún con alguna tonicidad, o al

\begin{abstract}
The present article deals with a revision of the analysis of one of the most present material structures in Nasrid rural milieu: the alqueria (farmstead) towers. Assumed until now its characterization as minor structures that were part of the Nasrid defensive system, we now launch a new interpretation proposal trying to understand until which point these constructions were the State's doing as part of its defensive or territorial control plans, or if, on the contrary, we find ourselves before a bastion of peasant communities self-management, from which it could depart the impetus of its building and use, opposite to other State-controlled spaces.
\end{abstract}

Key words: Nasrid, Power, Chronicles, Alquería

menos mantener ciertos resortes, el principio de tribalidad que hasta entonces había caracterizado la estructura de la sociedad islámica andalusi ${ }^{1}$. La base general de la que partimos asume como cierta la impresión de que en este último reducto de al-Andalus asistimos al triunfo de un estado islámico sobre una sociedad, también islámica, que se va diluyendo, en un progreso de degradación de las estructuras internas, marcadas, precisamente, por esos principios tribales, que hasta enton-

\footnotetext{
* Este artículo es fruto de los trabajos desarrollados en el marco del Proyecto de Investigación I+D "Los agentes locales del poder en el reino nazarí: impacto en la red social y capacidad de liderazgo" (HAR2011-24125), desarrollado en la Universidad de Granada (2012-2015) bajo la dirección de Adela Fábregas Garcia.

1. P. Guichard, Al-Andalus. Estructura antropológica de una sociedad islámica en Occidente, Barcelona 1976. Reed. Granada 1995 con estudio preliminar de Antonio Malpica; Idem, "Les rapports entre les villes et campagnes", en J.C. Garcin et alii, États, societés et cultures du monde musulman medieval. Tome 3. Problemas et perspectivas, Paris 2000, pp. 70-91; Idem, Al-Andalus frente a la conquista cristiana: los musulmanes de Valencia (Siglos XI-XIII), Valencia 2001; M. Barceló, "Saber lo que es un espacio hidráulico y lo que no lo es, o Al-Andalus y los feudales", en J. A. González Alcantud y A. Malpica Cuello, El agua, mitos, ritos y realidades, Granada 1992, pp. 240-254.
} 
ces la habían definido y habían constituido su fortaleza. En definitiva, se atiende desde todos los frentes a una afirmación del poder centralizado mucho más contundente en una sociedad islámica, en la que tradicionalmente habían estado separados el poder político del estado y la capacidad de gestión con alto grado de independencia las comunidades campesinas, fuertemente cohesionadas. Unas comunidades que habrían logrado hasta entonces preservar espacios de autonomía, cierto grado de impermeabilidad frente al ejercicio de dominación promovido por fuerzas ajenas a la propia comunidad, fueran éstas un Estado o cualquier otro tipo de poder señorial. El objetivo último es llegar a entender hasta qué punto esas antiguas comunidades rurales ostentaban aún cierta impermeabilidad frente a las formas de presión y dominio impuestas por formas de poder centralizado vigentes en los sucesivos Estados de al-Andalus.

Ese proceso de penetración de sistemas de poder externo, de origen estatal en este caso, en las antiguas estructuras comunitarias, parece experimentar una aceleración en la etapa final nazarí. No llegamos a entender del todo el origen de esta aceleración, pero lo que sí vamos detectando cada vez con más claridad y en más ámbitos son los signos de la misma. Quizás nos ayudaría a comprender la energía con la que el Estado asume su empresa hegemonizadora sobre el conjunto de la sociedad nazarí tener en cuenta algunas consideraciones. Por ejemplo, no debemos olvidar que se trata de un Estado marcado, como tantos otros pequeños gobiernos vigentes en el mundo islámico y surgidos a partir de la descomposición de la unidad política primitiva de la comunidad islámica, por una necesidad, casi acuciante, de consolidar, de legitimar al menos su mera existencia ${ }^{2}$; o que está embarcado en una nueva realidad regional, fuertemente influida por las tendencias expansivas que adoptan formas diversas, desde la expresión político territorial más evidente, por ejemplo, de la vecina Castilla, hasta la dinámica de generación de espacios económicos integrados y aglutinados en este momento por la fuerza del capitalismo comercial en el Mediterráneo occidental, a los que el espacio nazarí se incorpora.

Sea como fuere, lo cierto es que se observa un vigor renovado en la presencia, en la fuerza del Estado como forma de poder preponderante, a costa de la ya debilitada fortaleza de aquellos sistemas de gestión comunitaria aún existentes en el mundo campesino. Y todo ello constituye una novedad en la sociedad nazarí, marcando una línea de evolución bien definida y que la aleja de la conformación clásica de la sociedad islámica.

En todo caso el proceso de "desislamización”, que se precipita, no culmina en el mundo nazarí. Todo acabará de forma mucho más abrupta y definitiva a partir del trauma de la conquista castellana. De ahí que nuestro interés se centre en entender en qué punto de esa evolución nos encontramos realmente; observar las relaciones y tensiones que se establecen entre las dos grandes fuerzas constituyentes de la sociedad nazarí, el estado y las comunidades campesinas, a través del análisis de las formas que adopta la presencia y el grado de intervención que el Estado es capaz de asumir en el medio rural; e identificar, asimismo, los espacios de autonomía que aún son capaces de preservar esas comunidades campesinas, que constituyen su principal instrumento de resistencia frente a la dinámica hegemonizadora del Estado y en las que residen los últimos signos de su vitalidad. Y lo pretendemos realizar a partir de diversas vías de análisis, que no detallaremos aquí para no extendernos demasiado ${ }^{3}$.

2. M. I. Fierro, "La legitimidad del poder en el Islam”. Awraq, 15 (1994), pp. 147-184; P. Guichard, "El arabismo de los Estados taifas", en A. Malpica, R. Peinado, A. Fábregas (eds.), Actas del VII Coloquio de Historia de Andalucía. Qué es Andalucía. Una revisión histórica desde el Medievalismo, Granada 2009, vol. I, pp. 47-57; E. Molina López, "La dinámica política y los fundamentos del poder”, en R. Peinado Santaella(ed.), Historia del Reino de Granada. I: De los orígenes a la época mudéjar, Granada 2000, pp. 211-248; V. Martínez Enamorado V., "Lema de príncipes". Sobre la galiba y algunas evidencias epigráficas de su uso fuera del ámbito nazarí". Al Qantara, XXVII (2006), pp. 529-550.

3. Más detalles en A. Fábregas, "Local power agents in the Nasrid kingdom: their influence on social networks and leadership”, en Adela Fábregas y Flocel Sabaté (eds.), Power and rural comunities in al-Andalus: ideological and material representations, (en prensa). 
Sí tenemos que explicar, sin embargo, que consideramos que el análisis arqueológico, los vestigios materiales sobre los que se proyecte este proceso, una vez determinados los objetivos de estudio, tiene mucho que decir. En este sentido afrontamos la cuestión centrándonos en el análisis de la plasmación espacial de esa dinámica de antagonismo, como vía, si no para comprender en su totalidad el proceso de captación de esos grupos campesinos por parte del Estado, sí, al menos, para discernir su existencia, para comprobar su evolución.

Hay un tipo de estructura particular, cuyo análisis podría ayudar a realizar este recorrido: las llamadas torres de alquería a las que hemos hecho alusión.

\section{TORRES DE ALQUERÍA Y ESTRUCTURAS DEFENSIVAS EN AL-ANDALUS}

Existe una realidad material incontrovertible en algunos casos que no puede de ningún modo eludirse, ni en el reino nazarí de Granada ni en otros muchos espacios del Islam peninsular. Si no podemos pasar por alto la impresión que algunos observadores dejan escrita sobre una tierra densamente trabajada y poblada, que emerge de testimonios como el que se nos traslada en 1483 en una zona incluso fronteriza, como íllora ${ }^{4}$, espacios más protegidos como Guadix ${ }^{5}$, y cómo no, en la misma Vega de Granada ${ }^{6}$, tampoco podemos eludir la existencia de estructuras defensivas menores dispersas por el medio rural.

Desde luego parece poder asumirse el hecho de que esos elementos defensivos de carácter menor formen parte, compongan, junto con otros, el territorio rural nazarí. Una imagen que, en todo caso, y al menos en lo que respecta a las torres ubicadas en ese medio rural objeto de nuestro interés, no tiene más que un escaso reflejo en la realidad actual. A pesar de la constante presencia de torres, atalayas, castillos y otros elementos defensivos que componen una parte importante de los vestigios del paisaje del antiguo reino nazarí, lo cierto es que estos restos parecen constituir una pequeña parte de lo que pudo existir. Muchas de esas torres no han dejado rastros materiales visibles en un primer reconocimiento. Es cierto que una buena parte de las mismas simplemente dejaron de existir, escrupulosamente destruidas inmediatamente después o incluso a lo largo del mismo proceso de conquista, tal y como parece ocurrir con las torres de las alquerías de Cacín ${ }^{7}$ o Huéscar ${ }^{8}$, en la Vega de Granada, y por supuesto con posterioridad al mismo. Tampoco ayuda a una correcta identificación el hecho de que para la construcción de parte o de la totalidad de estas estructuras se recurriera al uso de materiales degradables, como la madera.

Con todo, aunque muy inferiores respecto a lo que debió haber a tenor de lo que

4. "... desde Illora la vía de Tánjara, derrocando y quemando todas las torres e alcarias e molinos que auía, e talando e quemando todas las huertas e panes e otras simientes, que auia mucho que talar...". Relación de las cosas que pasaron en la entrada quel Rey nuestro Señor fizo en el reino de Granada en el mes de Junio deste presente año (1483), editado por Duquesa de Berwicq y de Alba, Madrid 1891, pp. 18-42 (En adelante Alba).

5. “... se lanzaron a invadir los pueblos y aldeas próximos a Guadix, cuyos moradores se creían seguros de toda entrada repentina... Los moros que lograron refugiarse en los poblados y en las torres que acostumbran a levantar en los campos.... Alonso de Palencia, Guerra de Granada, Edición y estudio preliminar R. G. Peinado Santaella, Granada 1998, pp. 418-9 y 420 (En adelante Palencia).

6. "Basteçida la çibdat de Alhama, luego el Rey mandó mudar el real en la ribera del río Caçín, fasta vna legua de Alhama. E otro día fué a otro lugar que se llama Malahá; e mandólo quemar, e fueron derribadas y quemadas fasta trezientas torres, e cortijos, y alquerías, que estauan en aquel camino, y en dos leguas de su çircuyto...". Crónica de los Reyes Católicos por su secretario Fernando del Pulgar, editado por Carriazo, Juan de Mata, Carriazo, Vol. II, Madrid 1943, p. 79 (En adelante Pulgar).

7. "En este logar donde el Real se asentó estaba vn alcaría que se llamaua Caçín, con un cortijo e una torre buena, con su cerca gruesa e petril e almenas bien defendederas, e algo del cortijo estaua quemado, quel Rey nuestro Señor lo auia mandado quemar el año pasado. El alquería estaua despoblada, porque por temor de los de Alhama, no labrauan en esta comarca. El qual cortijo e torre mandó su alteza luego al thesorero Ruy López que tomase cargo de lo hazer derribar; e luego en esta misma noche el Thesorero no durmió, andando sobre los peones y dando orden como mas presto se derribase. Lo qual quando amáneselo estaua puesto por el suelo", Alba, p. 34

8. "Este dia el Rey mandó al secretario Francisco de Madrid que tomase cargo de derribar la torre que dicen de Huecar, que estaua Xenil ayuso, baxo del Real.... Derribóse por el pie toda la cerca del cortijo, e todas las casas e las bouedas todas, e la torre hasta la mitad lo que della quedó en fasto fue poco, e quedó tan aportillado e destruydo, que non se pueden aprovechar dello", Alba, p. 39. 
recogen las fuentes escritas, los vestigios que han sobrevivido son numerosos, muy numerosos, y conforman una percepción del paisaje nazarí tan densa como confusa. Al tratarse, en una primera observación, de estructuras defensivas, independientemente de su entidad, uno de los riesgos que podemos correr es asociarlas directamente y sin más consideraciones a un sistema defensivo promovido por un estado nazarí, que sabemos que puso gran empeño en organizar sistemas de control y protección del territorio bastantes sofisticados. Hay que decir que posiblemente esta primera impresión no corresponda a la realidad.

El intento de comprender la realidad territorial y política que podían indicar estas estructuras fue iniciado hace ya años desde la Arqueología, que pretendió entender en primera instancia el papel de las mismas como hitos de organización del territorio en el que se integraban, la naturaleza de las relaciones que mantenían con las unidades de poblamiento y que se propuso asimismo realizar un primer esfuerzo sistemático de catalogación y tipología de estas estructuras ${ }^{9}$.

Una primera diferenciación, la más evidente, consistió en distinguir las torres atalayas, aisladas y ubicadas en espacios de control estratégico, sin otras edificaciones asociadas, de las torres asociadas a alquerías u otros núcleos de asentamiento, y de las fortificaciones rurales o husun, edificios de mayor entidad que posiblemente acogieran destacamentos militares. En este último caso no debemos descartar, por lo observado en regiones concretas como las Alpujarras, que posiblemente procedan de estructuras anteriores, quizás, según se desprende del testimonio de Luis del Mármol, vinculadas a formas de control y autogestión de la sociedad rural, y que en un momento dado pudieran ser captadas y aprovechadas por el estado para organizar sistemas de control local sobre aquellas mismas poblaciones. En este sentido, podrían entrar también en nuestro campo de interés, aunque la necesidad de ir organizando el trabajo nos lleva a dejarlos a un lado por el momento.

Junto a estos elementos defensivos de mayor entidad y naturaleza aún por descifrar, destacan unas estructuras fortificadas de carácter menor, torres también, asociadas, de manera más o menos estrecha, con asentamientos reconocidos como alquerías, aunque no sólo, o bien con espacios de explotación campesina, que han dejado vestigios materiales suficientes como para no poder ser ignorados. Su presencia en el mundo rural nazarí, incuestionable, llama poderosamente la atención.

La existencia de estructuras similares en otros espacios del Islam peninsular, particularmente en las regiones levantinas, de donde surgió la propuesta inicial de un estudio firme y diferenciado de las mismas ${ }^{10}$ y donde con posterioridad han ido siendo estudiadas con mayor detalle ${ }^{11}$, ha llevado a una asimilación rápida de esas estructuras con lo que dio en llamarse torres de alquerías.

Se trata de un elemento mal conocido y lleno aún de enormes posibilidades a la hora de identificar un espacio en el que se pueden substanciar el grado y la naturaleza del vínculo

9. P. Cressier, “Le chateau et la division territoriale dans l'Alpujarra médiévale: du hisn à la Ta'a”. Melánges de la Casa Velazquez, 20 (1984), pp. 115-144; M. Acién Almansa, "La fortificación en al-Andalus". Archeologia Medievale XXII (1985), pp. 7-36; Idem, "Los tugur del Reino Nazarí. Ensayo de identificación”, en Castrum 5. Archéologie des espaces agraires méditerranéens au Moyen Âge, Murcia 1999. pp. 427-438; Antonio Malpica Cuello, Poblamiento y castillos en Granada, Barcelona 1996; Idem, "Los castillos en época nazarí. Una primera aproximación”, en Castillos y territorio en al-Andalus, Granada 1998, pp. 246-293; Idem, Los castillos en Al-Andalus y la organización del territorio, Cáceres 2003.

10. P. Guichard y A. Bazzana, "Les tours de défense de la huerta de Valence au XIIle siècle”. Mélanges de la Casa de Velázquez, 14 (1978), pp. 73-105.

11. J. Torró, "Fortificaciones en Yibal Balansiya. Una propuesta de secuencia", en A. Malpica Cuello (ed.), Castillos y territorio en Al-Andalus..., pp. 385-418, espec. pp. 408-412; P. López Elum, Los castillos valencianos en la Edad Media (materiales y técnicas constructivas), Valencia 2002; P. Rodríguez Navarro, La torre árabe observatorio en tierras valencianas. Tipología arquitectónica, Valencia 2008, tesis doctoral (http://dspace.upv.es/xmlui/handle/10251/3542); y para el caso de Murcia I. Díaz García, La huerta de Murcia en el siglo XIV: propiedad y producción, Murcia 1990. 
que liga al poder con esas comunidades locales. De ahí que hayamos elegido el estudio de estas edificaciones como objetivo estratégico para avanzar en el conocimiento de estas formas de podery de los instrumentos de control y dominación a que recurre en el mundo rural. La cuestión fundamental sería entender hasta qué punto estas construcciones son obra de la iniciativa estatal y de esos planes defensivos o de control territorial que pone en marcha, o si por el contrario, tal y como propuso Guichard en su momento para el caso valenciano, estamos ante un reducto de autonomía de gestión de las comunidades campesinas, de las que podría partir el impulso de su construcción y uso, frente a otros espacios de control estatal.

\section{TORRES DE ALQUERÍA EN TERRITORIO NAZARÍ. ALGUNAS REFLEXIONES}

A partir de la aplicación de ciertos criterios propuestos de manera muy general, se han ido realizando diversos esfuerzos de identificación en territorio nazarí ${ }^{12}$ y de la mano de estos primeros acercamientos, ha habido intentos, quizás algo precipitados, de proponer definiciones que pudieran ser aplicadas a este término y dieran cabida a todas las estructuras localizadas en el medio rural hasta el momento. Se ha llegado a exponer que se trata de "torres que, situadas generalmente en lugares llanos o en pie de monte, se encuentran próximas a una o varias alquerías, sirviendo de refugio, en caso de peligro, a los habitantes de zonas que no disponían de acceso rápido a un castillo o fortaleza de mayor entidad" ${ }^{13}$. Se han añadido también explicaciones acerca de sus características estructurales, constitu- yendo un tipo y contribuyendo a generar la impresión de que se tiene una idea siquiera aproximada acerca de lo que en realidad es una torre de alquería.

Lo cierto es que, conforme avanza, lentamente, nuestro conocimiento acerca de las Ilamadas "torres de alquería", aumenta también la conciencia de encontrarnos ante un cajón de sastre en el que todo cabe, en el que nada se entiende realmente. De hecho, por ejemplo, podríamos ya decir que la mayor parte de esos elementos definitorios resultan extraordinariamente relativos.

Se trata de una impresión que confirman los mejores estudios llevados a cabo hasta el momento sobre ejemplos específicos de algunas de estas construcciones, y que ponen de manifiesto la evidente complejidad y diversidad que se recoge dentro de este término. Torres situadas en asentamientos como el Bordonar ${ }^{14}$ parecen poder diferenciarse claramente de las localizadas en otras alquerías de la zona como Las Gabias, Romilla o Cijuela. En el caso de las Gabias, la función residencial de la torre parece destacar por encima de cualquier otra consideración. Y resulta interesante observar la existencia de otros ejemplos, como el localizado en Lanteira, que los autores del estudio llevado a cabo sobre la misma equiparan con el caso de la Torre del Tío Vayo, en el Valle de Lecrín, en los que la misma alquería acoge dos o más estructuras defensivas de distinto tipo ${ }^{15}$.

Son, todas ellas, torres situadas en alquerías, sí. Pero ¿podemos a partir desu mera ubicación, equiparar unas a otras, incluirlas de manera

\footnotetext{
12. L. Torres Balbás, "La torre de Gabia (Granada)”. Al-Andalus XVIII (1953), pp. 187-198; Idem, "La torre de Gabia la mayor, desmochada". en Al-Andalus XXI (1956), pp. 375-377; A. Almagro Gorbea, "La torre de Romilla. Una torre nazarí en la Vega de Granada". Al-Qantara, XII (1991), pp. 225-250; A. Malpica Cuello, Poblamiento y castillos...; Idem, "La alquería nazarí de Bordonar en la Vega de Granada". Estudios de historia y arqueología medievales, IX (1996), pp. 313-348; M. Martín García, "Torres de alquería de la provincia de Granada", en Actas del Tercer Congreso Nacional de Historia de la Construcción, Sevilla 2000, pp. 651-664; M. Jiménez Puertas, "Asentamientos rurales y frontera: las torres de alquería de la tierra de Loja en época nazarí", en C. Trillo San José, Asentamientos rurales y territorio en el Mediterráneo medieval, Granada 2002, pp. 390-421; M. Jiménez Puertas, G. García-Contreras Ruiz, L. Mattei, "El fuerte de Lanteira (Granada). Análisis de una fortificación de alquería en época nazarí. Arqueología de la Arquitectura, 7 (2010), pp. 191-211; M. Martín García, "Torres de alquería de la Vega de Granada”. PH. Boletín del Instituto Andaluz de Patrimonio Histórico, 74 (2010), pp. 46-54.

13. M. Martín García, "Torres de alquería de la provincia ..., p. 651.

14. A. Malpica Cuello, "La alquería nazari de Bordonar...".

15. M. Jiménez Puertas, G. García-Contreras Ruiz, L. Mattei, "El fuerte de Lanteira ...."
} 
indiscriminada en un mismo grupo funcional? ¿Qué son en realidad las torres de alquerías?

Una de las claves para su distinción podría venir marcada por su vinculación o su inclusión en propiedades de titularidad privada. En más de una ocasión se declara abiertamente su adscripción a la casa real nazarí. Éste, según declara Antonio Malpica, puede ser el caso de algunas de las hasta ahora llamadas torres de alquería más famosas, como la de Romilla, declarada abiertamente como de titularidad real ${ }^{16}$, y la torre de las Gabias. Es el caso también de las edificaciones ubicadas en la alquerías de Ascorosa ${ }^{17}$ o de Cijuela ${ }^{18}$, ambas en la Vega de Granada. Y las puede haber también marcadas por una faceta residencial clara, como puede ocurrir en la Torre de las Gabias ${ }^{19}$, o posiblemente vinculadas a formas de propiedad individual, en más de una ocasión, aunque no siempre, a la casa real nazarí. En este caso su naturaleza posiblemente no tenga nada que ver con lo que a nosotros nos interesa y, a la espera de mayores avances en la investigación, precisamente el testimonio de algunas fuentes escritas nos puede dar algunas pistas esenciales para establecer esta diferencia, que debe ser confirmada, como decimos, a través de un análisis arqueológico profundo.

Así que en realidad nos encontramos con estructuras defensivas, vinculadas a asentamientos rurales, a alquerías, sí; de manera directa o indirecta asociadas a esos asentamientos, ubicadas en espacios productivos, en huertas, pero que pueden también tener distintas funciones y naturaleza y que conviene diferenciar de forma sistemática. El trabajo, liderado desde la Arqueología, planteado prevalentemente a partir de una propuesta de comprensión de vestigios materiales, no parece poder eludir en ningún caso un análisis que trascienda la mera descripción formal de estructuras que llevarían indefectiblemente a la confusión. Su comprensión como plasmación material de los procesos de conformación y evolución de la sociedad que las crea parece del todo inevitable a la hora de comprender su naturaleza, de conocer su realidad como parte del proceso histórico.

A partir de este presupuesto se ha iniciado un trabajo de investigación en torno a la caracterización de estas estructuras en el mundo rural nazarí. El objetivo inicial, demasiado ambicioso según hemos entendido con posterioridad al inicio de las tareas, que comprendía la totalidad del territorio nazarí, ha quedado restringido por el momento a la mitad oriental del reino, reservando otras zonas como objetos susceptibles de ulteriores ampliaciones del proyecto. De este modo se ha identificado como espacio de estudio el área oriental del antiguo territorio nazarí comprendida en el Surco Intrabético, es decir, depresión de Granada, hoyas de Guadix, Baza y Huéscar.

Y para ello puede contar con el apoyo puntual y limitado, subsidiario en todo caso, de otras vías de análisis histórico, entre ellas la que ofrece el recurso a la documentación escrita.

\section{LA APORTACIÓN DE LA DOCUMENTA- CIÓN ESCRITA}

En una primera guía que se pueda ofrecer al análisis arqueológico, desde el documento escrito, y que se nutriría también a través de

\footnotetext{
16. A. Malpica Cuello, "La alquería nazarí de Bordonar..., p. 320. El autor argumenta esta consideración, entre otras cosas, en el texto de Ibn al-Jatib que describe la alquería de Romilla, Ruma, incluyendo en la misma un castillo y un jardin ("...wa qaryat Ruma wa biha hisn wa bustan..." Ibn al-Jatib, Al Ihata fi ajbar Garnata, ed. A. Inan, El Cairo 1955 y 1973-1978, vol. I, p. 125), y dejando claro, a partir de lo escrito en la Crónica del Halconero de Juan II que se trataba de un alcaçar del rey ("...Roma, que era donde estaua el alcáçar del rrey"). P. Carrillo de Huete, Crónica del halconero de Juan II, Ed. Juan de Mata Carriazo, Madrid 1946, cap. LXXXII, pp. 99-100 (En adelante Halconero).

17. "De los logares que fueron quemados en tierra de Granada: (...) Escuraja, que era otra aldea muy buena, donde estaua otro alcáçar del rrey". Halconero, p. 99.

18. (...) Ezixuela, donde estaua el alcáçar del rrey, que era la mejor e más rrica casa que é tenía después del Alfanbra, do façía sus anaçeas". Halconero, LXXI, LXXXII, p. 99.

19. A. Malpica Cuello, "La alquería nazarí de Bordonar...", p. 322.
} 
otras vías tan esenciales como el rastreo toponímico, podría resulta fundamental intentar reconocer el mayor número de torres existentes en época nazarí. Resulta un primer paso obligado, sobre todo si tenemos en cuenta la intensidad del proceso de destrucción de las mismas que ha llegado hasta nuestros días, de manera que una simple identificación a partir de los restos visibles resultaría del todo imprecisa e inexacta. Las fuentes escritas nos ofrecen datos en más de una ocasión de torres de las que no tenemos en apariencia ninguna traza en la actualidad. Quizás la vinculación de torres con espacios de asentamiento pueda darnos pistas al respecto. Y para ello la identificación, en la medida de lo posible, de los asentamientos que pueden ser reconocidos como alquerías en el mundo nazarí, resultará crucial. La cuestión presenta sus dificultades, entre las que no es menor tratar de diferenciar en estos asentamientos, cuales de ellos se adscriben directamente a este grupo y cuales pueden ser identificados como villas fortificadas. Así, por ejemplo, en zonas de marcado carácter fronterizo, algunos de los asentamientos de presencia más constante en las fuentes, de cuya lectura podría desprenderse una identificación primera con alquerías de una tierra determinada, en realidad deben ser identificadas -y de hecho lo han sido- como villas fortificadas. La cuestión se pone claramente de manifiesto a partir del análisis realizado por Antonio Malpica para, por ejemplo, la tierra de Baza. Sin embargo, las alquerías - colindantes según el mismo Libro de Repartimiento de Baza- de Caniles, Zújar, Benamaurel, Cúllar, Benzalema y Cortes deben adscribirse a este grupo de poblaciones defensivas típicas de la organización fronteriza nazarí ${ }^{20}$. A la hora de identificar torres y vincularlas a núcleos de asentamiento, la naturaleza de la fuente determina, como casi siempre, la calidad de los datos ofrecidos. Y en este sentido quizás el trabajo que pueda ofrecer más resultados, aunque no exclusivamente, sea el de rastreo sistemático de libros de Apeos y Repartimientos de las localidades del antiguo reino nazarí. Corresponden a un tipo de fuentes que, con una lectura adecuada, han comenzado a dar unos frutos de alcance considerable, como muestran en concreto para tierras malagueñas los casos de la tierra de Marbella y el sistema de alquerías desarrollado en torno a Torrox ${ }^{21}$. De todos modos hay que tener en cuenta que, según veremos más adelante, no podemos afirmar con rotundidad una asociación estricta y exclusiva de estas estructuras con un asentamiento, pudiendo darse casos en los que una de estas estructuras es punto de encuentro de varias comunidades.

Del mismo modo resulta importante intentar apurar la adscripción cronológica de las mismas, tarea asumible a partir del análisis de modelos constructivos, pero en la que el recurso a ciertas informaciones documentales, sobre todo procedentes de la época inmediatamente posterior a la conquista castellana, también pueden permitir discriminar en muchos casos estructuras anteriores y nuevas edificaciones surgidas al calor de la organización militar, de defensa y vigilancia del nuevo Reino de Granada.

Pero, aparte de una identificación primera de las torres susceptibles de estudio, aportando un listado más o menos limpio de las mismas, deberíamos buscar en la documentación algo más. Es evidente, por ejemplo, la necesidad de aclarar la verdadera entidad de una estructura que en el documento es considerada de manera genérica como una torre, sin añadir más informaciones al respecto. Abordar una caracterización de su naturaleza y funciones. Y aquí es donde entramos verdaderamente en materia. Porque sólo a partir de un acercamiento siquiera básico a la naturaleza y funciones de estas estructuras, tomamos conciencia de la enorme diversidad de realidades que se engloban en las conocidas como torres de alquería.

20. A. Malpica, Poblamiento y castillos ..., pp. 135-136.

21. Virigilio Martínez Enamorado, Torrox. Un sistema de alquerías andalusíes en el siglo XV según su Libro de Repartimiento, Granada 2006; Idem, Cuando Marbella era una tierra de alquerías: sobre la ciudad andalusí de Marballa y sus alfoces, Marbella 2008. 
En este punto el análisis de la documentación escrita suele aportar pocas informaciones, e incluso, llegado el caso, contribuye a generar confusiones importantes. En realidad son pocas las ocasiones en que se nos ofrecen datos relevantes, aunque cuando aparecen resultan de ser de vital importancia a la hora de contribuir a la verdadera caracterización de las torres de alquería, como veremos más adelante.

\section{LAS TORRES DE ALQUERÍA EN LA CRONÍSTICA CASTELLANA}

Con objeto de realizar una primera aproximación a estas cuestiones, en esta ocasión hemos decidido afrontar el rastreo de un grupo de fuentes escritas muy determinado, el formado por todo el ciclo de la cronística castellana contemporánea de la época nazarí, desde la de Alfonso XI, la primera de la que podemos extraer noticias, hasta las crónicas de los Reyes Católicos. ${ }^{22}$ Se trata de un corpus documental que hemos completado con otro grupo de crónicas, las procedentes de casas nobiliarias, destacando en este caso los Hechos del Marqués de Cádiz y del Condestable Lucas de Iranzo, además de informaciones procedentes de los primeros años de la administración castellana del Reino de Granada, reconocidos a partir de la correspondencia del secretario real Hernando de Zafra y del gobernador general del Reino de Granada, el Conde de Tendilla. ${ }^{23} \mathrm{El}$ recorrido lo cierra el relato de Luis del Mármol sobre la rebelión de los moriscos. ${ }^{24}$

Antes de entrar en materia cabe tener presente la naturaleza y las limitaciones de estas fuentes. En primer lugar, los datos que se recogen contienen testimonios tamizados por el prisma cristiano, que no siempre comprendía certeramente lo que ponía por escrito. En segundo lugar, no se puede olvidar tampoco el factor ideológico y propagandístico que preside estos textos, de exaltación de la élite de la sociedad feudal castellana, encabezada por el rey y los grandes nobles del reino, obligados a la guerra del moro como factor de legitimación generación tras generación. ${ }^{25}$ Así, las informaciones recopiladas están básicamente ligadas a empresas depredatorias, de pequeña entidad en su inmensa mayoría -cabalgadas castellanas en territorio granadino- o más puntualmente verdaderas confrontaciones armadas, como la batalla de La Higueruela (1431), siempre dependientes de las circunstancias internas de la Corona de Castilla. De hecho, las dificultades en el reinado de Enrique II (1369-1379), por ejemplo, hacen que toda la atención castellana se centrara en asentar y legitimar el ascenso de la nueva dinastía Trastámara, olvidando momentánea-

22. Se han consultado las siguientes ediciones. Para las crónicas desde Alfonso X el Sabio hasta la de Juan II de Castilla se ha recurrido a la colección ordenada por Cayetano Rosell, publicada por la Biblioteca de Autores Españoles: Crónicas de los Reyes de Castilla, desde Don Alfonso el Sabio hasta los católicos Don Fernando y Doña Isabel, Madrid, Atlas, 1953 (3 tomos); para los reinados posteriores se ha recurrido a la Crónica de Enrique IV de Diego Enríquez del Castillo, Valladolid 1994; Crónica castellana de Enrique IV de Castilla, edición crítica y estudio de M. a del Pilar Sánchez-Parra García, Murcia 1985; Memorial de diversas hazañas: crónica de Enrique IV ordenada por mosén Diego de Valera, edición y estudio por Juan de Mata Carriazo, Madrid 1941; Crónica de Enrique IV, escrita en latín por Alonso de Palencia, traducción castellana por D. Antonio Paz y Meliá, Madrid 1904; Alonso de Palencia, Guerra de Granada, estudio preliminar por Rafael Gerardo Peinado Santaella, Granada 1998 (En adelante Palencia); Andrés Bernáldez, Memorias del reinado de los Reyes Católicos, edición y estudio por Manuel Gómez-Moreno y Juan de M. Carriazo, Madrid 1962 (En adelante Bernáldez); Hernando del Pulgar, Crónica de los Reyes Católicos...; Mosén Diego de Valera, Crónica de los Reyes Católicos, edición y estudio por Juan de M. Carriazo, Madrid 1927 (En adelante Valera).

23. Emilio Meneses García, Correspondencia del Conde de Tendilla (1508-1513), Madrid 1973; Epistolario del Conde de Tendilla (15041506), estudio de José Szmolka Clares; edición y transcripción de M.a Amparo Moreno Trujillo y M.a José Osorio Pérez, Granada 1996; Escribir y gobernar: el último registro de correspondencia del Conde de Tendilla (1513-1516), M. Amparo Moreno Trujillo, M. ${ }^{a}$ José Osorio Pérez y Juan M. a de la Obra Sierra, Granada 2007 (En adelante Tendilla); Juan M. ${ }^{a}$ De la Obra Sierra, Correspondencia de Hernando de Zafra, Granada 2011.

24. Luis del Mármol Carvajal, Historia de la rebelión y castigo de los moriscos del Reino de Granada, Granada 1997 (En adelante Mármol Carvajal). Recientemente ha sido publicada una nueva edición a manos de Javier Castillo Fernández, Historia del rebelión y castigo de los moriscos del reino de Granada, Granada, 2015. En todo caso nuestro trabajo ha sido elaborado a partir de la consulta de la edición de 1997.

25. En este punto todavía resultan muy útiles los trabajos contenidos en el volumen Ensayos sobre la Historiografía Peninsular del Siglo XV, Madrid 1970. 
mente la secular guerra del moro. Más adelante las luchas intestinas durante el reinado de Enrique IV (1454-1474) hicieron prevalecer las iniciativas nobiliarias sobre las reales, por lo que son cruciales las informaciones que en este caso proporcionan las crónicas de don Álvaro de Luna y del Condestable Lucas de Iranzo. ${ }^{26}$

Naturalmente, el carácter y el alcance de estas expediciones hace que las informaciones que se puedan recopilar para los siglos XIV y XV se limiten a las zonas de frontera donde había mayor actividad militar, básicamente la Serranía de Ronda y el valle de Ardales en el sector occidental, fruto de las entradas desde las localidades del Reino de Sevilla, y la Vega de Granada en el sector central, objeto de las depredaciones procedentes de los Reinos de Córdoba y Jaén. En comparación, las informaciones que la cronística castellana ofrece para el sector oriental son mucho más limitadas. En su caso hay que esperar a la época de los Reyes Católicos, cuando la conquista paulatina y sistemática del territorio, perfectamente detallada en las crónicas de Bernáldez, Palencia, Pulgar y Valera sobre la Guerra de Granada, proporcione informaciones inéditas sobre zonas más resguardadas del resto del reino ${ }^{27}$. En última instancia la crónica de Luis del Mármol completa el panorama con las noticias procedentes de las Alpujarras, si bien hay que tomarlas con mayor cautela por ser un testimonio posterior en un siglo a la extinción del último Estado musulmán de la Península. Se trata de una vía que, como ya hemos comentado, en el futuro habrá que complementar con los datos procedentes de los Libros de Apeos y de Repartimiento que los conquistadores castellanos llevaron a cabo en todo el territorio granadino, a excepción de la capital.

Por otra parte, la naturaleza de las fuentes abordadas justifica en buena medida que los sucesos trasladados, y la forma de narrarlos, se muevan con una cierta rigidez entre los principales hitos de organización de un sistema de poblamiento percibido por los visitantes a partir, fundamentalmente, de criterios estrictamente defensivos. Destacan siempre los grandes ejes de vertebración de la defensa del territorio, objeto de sus ataques, quedando más oscurecida la escala microregional. Los puntos de referencia que utiliza el observador ajeno son preferentemente ciudades y grandes espacios fortificados.

Castillos, fortalezas, núcleos fortificados de mayor o menor entidad y atalayas facilitan la definición de los perímetros de influencia y ayudan a organizar el poblamiento y la estrategia invasiva del agresor. En la mayor parte de los casos se trata de espacios fortificados en los que se detecta una presencia clara y contundente de elementos ajenos a la población de la zona, en los que el poder central se ve representado de manera patente, pero que no por ello dejan de estar integrados en la estructura poblacional de la región, entre otras cosas porque se trata de espacios habitados si atendemos a la denominación de villa y fortaleza con que se citan muchas de ellas.

Pero, aún así, en algunos casos, no numerosísimos, aunque sí muy reveladores, aparecen otros elementos menores. Y es que las necesidades defensivas de una población determinada no siempre se resuelven del mismo modo. De hecho, en la mayoría de los casos no existe una relación estrecha entre población de las alquerías y grandes espacios fortificados ubicados en las mismas como sistemas de protección. Generalmente, cuando son atacados los individuos de estas alquerías, acuden a otro tipo de soluciones defensivas, que van desde la huída hasta el encierro desesperado en los recintos fuertes de su población, que en más de una ocasión coinciden precisamente con las torres ubica-

26. Crónica de don Álvaro de Luna, Condestable de Castilla, Maestre de Santiago, edición y estudio por Juan de Mata Carriazo, Madrid 1940; Catherine Soriano, Los hechos del Condestable don Miguel Lucas de Iranzo: estudio y edición, Madrid 1993 (En adelante Iranzo).

27. Habría que incluir aquí la Relación de las cosas que pasaron en la entrada quel Rey nuestro Señor fizo en el reino de Granada en el mes de Junio deste presente año (1483), publicada en Duquesa de Berwick y de Alba, Documentos ..., pp. 18-42. 
das en las mismas. Este punto llevó a considerar en muchos casos y a lo largo de mucho tiempo la naturaleza estrictamente defensiva de nuestras torres de alquería como espacios de protección para la población residente en esa alquería.

Pues bien, a través de la lectura de estas fuentes, y más allá de confirmar la evidente finalidad de proteger que pueden desempeñar esas torres, nuestras impresiones acerca de las mismas, que nos esforzamos por desarrollar sin apriorismos que fuercen o desvirtúen la reflexión, se plantean más bien como una invitación a consideraciones futuras, que permitan profundizar mejor en la verdadera naturaleza de estas estructuras.

\section{1 ¿Qué o a quién se protege?}

La primera cuestión que podríamos lanzar es, una vez establecida como cierta su función protectora, qué o a quién protegen estas torres ubicadas en las alquerías. Ya lo hemos anunciado. La idea más comúnmente aceptada es que se trata de una vía de defensa de la población de la alquería frente a ataques externos. López Elum, en su estudio sobre las torres de alquería de Valencia, acentúa hasta el extremo la naturaleza estrictamente defensiva de las mismas, proponiendo su inclusión en un sistema defensivo de entornos urbanos, alrededor del cual surgirían con posterioridad asentamientos asociados ${ }^{28}$. La investigación posterior en la zona ha ido demostrando que esta secuencia cronológica de constitución de los entornos periurbanos no se corresponde con lo que ha ido arrojando el análisis arqueológico. En todo caso, no podemos de ningún modo ignorar las capacidades defensivas que ofrecen estructuras de estas características. Podría ser cierto en alguna ocasión y justificar sobradamente su existencia.

De hecho, una idea comúnmente aceptada y utilizada es que, también aquí, en territorio nazarí, son estructuras defensivas levantadas con el objetivo prioritario de defender a la población indígena residente en el medio rural de los ataques de fuerzas castellanas, preservando la integridad de las personas y de sus bienes ${ }^{29}$. No son estructuras propias de espacios fronterizos, su finalidad no es evitar la conquista, sino paliar los efectos de ataques ${ }^{30}$. Y lo cierto es que conocemos ejemplos, testimonios de poblaciones que se resguardan de agresiones puntuales ${ }^{31}$. Y algo más tarde el mismo Luis del Mármol da como cierta esa función eminentemente defensiva de muchas de estas torres ${ }^{32}$. Incluso se propone el uso de algunas estructuras como espacio de defensa de varias alquerías ${ }^{33}$, como podría ocurrir en la torre de Marchena, situada en pleno Valle de Lecrín granadino, que parece cumplir también esa función de refugio para varias poblaciones cercanas ${ }^{34}$.

28. Pedro López Elum, Los castillos valencianos ..., vol. I, pp. 87 y ss.

29. M. Jimenez Puertas, "Asentamientos rurales y frontera...”; M. Martín García, "Torres de alquería...."

30. M. Jimenez Puertas, "Asentamientos rurales y frontera..., p. 393.

31. "E como el dia a mas andar se venía, corrió a rienda suelta tres leguas grandes, fasta que llegó a un lugar que dizen la Malahá. E como ya los moros estavan aperçebidos, anparáronse en una fuerte torre que ende tenían, pero el lugar luego fue entrado e robado e quemado...". Iranzo, p. 170; "E commo el maestre traxese la çaga e pasase por vna aldea que se llamaua Moclinete, que se avía quemado, los moros que se avían retraydo a vna torre, salieiron della e dieron en la çaga de la batalla...". Historia de los Hechos del Marqués de Cádiz. Estudio preliminar, edición e índices de Juan Luis Carriazo Rubio, Granada, Universidad de Granada, 2003, p. 219 (En adelante M. de Cádiz). Por su parte Andrés Bernáldez cuenta que "... el rey se bolvió a la Vega de Granada, e de buelta tomaron la torre de Gandía, donde se tomaron treinta moros", Bernáldez, capítulo C, p. 224, 1491.

32. "Que trata del levantamiento general de los moriscos de la Alpujarra": "a los que se recogían en las torres y lugares fuertes los cercaron y rodearon con llamas de fuego". Mármol Carvajal, Libro IV, Capítulo VIII.

33. "Por aver seydo sentidos, todos los moros, con lo prinçipal de lo que tenían, se alçaron a las torres e a lo más agro de la sierra, en tal manera que ninguno se tomó, saluo quinze moros e diez moras que algunos de los del marqués tomaron en vna aldea que el marqués entró...". M. de Cádiz, p. 219. Más claro aún en este sentido es Diego de Valera en un pasaje extraordinariamente parecido al anterior: "De su tardança ovieron de ser sentidos, e todos los moros estavan alçados en las torres de las aldeas, que ninguno se tomó, salvo diez moras e quince moros que los del marqués tomaron en una aldea.... Valera, p. 162.

34. A. Malpica Cuello, "La alquería nazarí de Bordonar..., p. 323. L. Reyes Castañeda, "Técnicas de construcción de las fortificaciones en el reino de Granada”, en Actas del I/ Simposio Internacional del mudejarismo, Teruel 1986, pp. 373-388. 
Pero posiblemente no sea esta su función cotidiana, o prioritaria. Primero porque, efectivamente, tal y como llegó a temer en algún momento Acién, es dudosa la capacidad que puedan tener estos recintos para acoger a la población completa. Sería necesario conocer la población de una alquería, pero se hace difícil pensar que sea así. Lo cierto es que cuando hay una percepción clara del peligro, cuando se tiene constancia de la proximidad de agresiones evidentes, la población rural tiende a huir, si es posible a espacios de protección mucho más sólidos ${ }^{35} \mathrm{O}$ aislados, de difícil acceso ${ }^{36}$. De hecho en alguna ocasión se plantea que la gente del pueblo ha huido, dejando la torre sola. O prácticamente sola. La torre queda defendida por pocos indivi- duos, no por la alquería entera ${ }^{37}$; individuos que no se resguardan allí, sino que están protegiéndola. Esos individuos están defendiendo algo que va más allá de su propia integridad personal. Están defendiendo la torre, y cuando la abandonan, ésta queda desamparada ${ }^{38}$. La torre y lo que contiene la torre ${ }^{39}$.

Quizás el análisis de la estructura arquitectónica de estas torres ayude a entender este extremo algo mejor. Son espacios articulados, compuestos por dos o más estructuras, que en más de una ocasión los castellanos asimilan a cortijos ${ }^{40}$. Tienen la torre y una cerca o muro perimetral, que acoge ganado, tal y como muestran algunos testimonios ${ }^{41}$. Situadas en

35. "...Ya los moros, por temor de las entradas pasadas, aviendo por çierta su total destruiçión, segund el miedo que d’este señor avién conçebido, e sabiendo que todo su deseo e deleite era continuar e proseguir contra ellos la guerra, despoblavan la tierra llana e desanparavan los lugares mal çercados, e recogíanse a las fortalezas e a los lugares más populosos, e dexavan perder las lavores del pan e la cría de los ganados e la administraçion de sus heredamientos, por manera que ya d'ellos no se esperava sino toda citoria.... Iranzo, p. 175.

"Los moros que lograron refugiarse en los poblados y en las torres que acostumbran a levantar en los campos avisaron a los suyos con humaredas del desastre sufrido. (...) Ya sólo al amparo de las murallas de Guadix se creían seguros los campesinos...." Palencia, pp. 418- 420.

"Quedaron esta noche por baxar en la fortaleza en vna torre della fasta treynta e quatro moros e seys moras viejas, que no auia mas, porque, las mugeres e la otra gente menuda e catiuos auian enviado a Loxa, e no auian quedado alli mas de doscientos e cinquenta onbres de pelea...." Fortaleza de Tajarja, Alba, p. 30.

36. "E commo los moros la oyeron así de lexos, ovieron logar de se saluar todos e lleuar lo mejor que tenian a la sierra. Y con todo eso fallaron en la villa muchas joyas e cosas moriscas e oro e plata e otras muchas preseas de casa. E sacaron dende muchos bueyes e vacas e cabras e ovejas...". M. de Cádiz, 196.

37. "...e todos la combatieron de guisa que [la torre] fue derribada con grandes tiros de pólvora, en la qual estaban nueve moros, de los quales cinco fueron muertos e los quatro fueron presos...". Torre de Pinos Puente, 1431, Crónica de Juan II, cap. XVII, p. 497.

38. "... mandó que combatiesen la torre, la qual combatieron dos días, e no la pudieron tomar. E como los moros vieron que los christianos no se partían dende, fuéronse de noche, e desampararon la torre”. Torre de las Cuevas. Crónica de Juan II, Cap. XLV, p. 296.

39. “...e como el infante lo supo, mandó a Diego Hernández de Quiñones que fuese a combatir las Cuevas, e cuando él llegó, los moros de noche habian dexado la fortaleza, en la qual hallaron asaz trigo e cevada e higos e mucha ropa, e otras cosas; y el Infante mandó en todo poner buen recabdo". Torre de las Cuevas, Crónica de Juan II, Cap. XLV, p. 296.. "... una torre fuerte que estaua fasta quatro tiros de ballesta de Tánjara, camino de Loxa, para la combatyr, que estauan en ella ocho moros que la guardauan; e antes que la combatiesen, se dieron, e tomaron la torre e cativaron los moros, e tomaron en ella fasta seyscientas fanegas de trigo e cenada e otras cosas de bastimento". Alba, 31.

40. "E como supo el Rey que estauan yermas, mandó derribar todas las torres e muros que cortijos que tenían. Otrosy mandó derribar la torre [del Atabal, e otra fuerza que se dezía la torre] nueva del Quiçote". Pulgar, pp. 160-161; "En este logar donde el Real se asentó estaba vn alcaría que se llamaua Caçín, con un cortijo e una torre buena, con su cerca gruesa e petril e almenas bien defendederas, e algo del cortijo estaua quemado, quel Rey nuestro Señor lo auia mandado quemar el año pasado. El alquería estaua despoblada, porque por temor de los de Alhama, no labrauan en esta comarca... Alba, p. 36.

41. "...tomaron la torre de Roma, que está dos leguas de Granada, por una muy gentil arte: tomaron ciertos moros, de los que venían en servicio del rey, una mañana, ciertas reses e dos cristianos maniatados, e fuéronse para la torre diziendo que traían cavalgada, que les abriessen, que no avían donde fuessen por guarescer sino alli. E como los de la torre conoscieron que eran moros, abrieron e saliéronles a recebir; e ellos entonces tomáronles la torre con cuanto en ella estava.... Bernáldez, cap. XCVI, p. 217; “...derribar la torre que dicen de Huecar, que estaua Xenil ayuso, baxo del Real. Era una torre gruesa de argamasa muy fuerte, de quatro bouedas, e baxo, su algibe e mazmorra, con su cortijo muy fuerte al derredor della, de argamasa, con algunas casas á que se acogían e defendían muchos de los labradores e ganados de la Vega, e desde ella rescibian dapno los cristianos e corredores e los que entran en almogaueria, e en tienpo de paces, se ascondian en ella los cristianos furtados.

Este dia, lunes, e martes syguiente, estouo en ella. Derribóse por el pie toda la cerca del cortijo, e todas las casas e las bouedas todas, e la torre hasta la mitad lo que della quedó en fasto fue poco, e quedó tan aportillado e destruydo, que non se pueden aprovechar dello". Alba, p. 39. 
espacios accesibles dentro del perímetro de trabajo de la alquería, en muchas ocasiones se encontraban ubicadas dentro del mismo asentamiento -aunque no necesariamente-, y en todo caso siempre dentro de su espacio productivo $^{42}$.

De hecho, es posible que esa vinculación a los espacios de asentamiento no sea tan definitiva como su vinculación a espacios productivos o a áreas de explotación ganadera. Porque una función importante que pueden tener estas torres, además de contener una parte de la producción agrícola de la alquería, como se ha visto, es la de recoger, amparar el ganado. De ahí que estén dispuestas a acoger el ganado de manera "indiscriminada", tal y como nos muestra el ardid usado para la toma de la torre de Romilla ${ }^{43}$. Queda mucho por saber, pero puede que se trate de bases de apoyo, estructuras de acogida y almacenamiento de los excedentes vinculados a espacios productivos, agrícolas y ganaderos. De ahí también las grandes cantidades de cereal almacenado que encontraban los cristianos en torres abandonadas ante su llegada, o conquistadas. Si esto es así, entonces ¿hasta qué punto el Estado está presente? ¿En calidad de qué?

\section{2 ¿Quiénes se defienden? Los promoto- res de las torres de alquería}

A esta primera cuestión, qué y a quiénes se protege, sigue una segunda, propuesta desde la lógica más aplastante: ¿quiénes se defienden? Aquí es donde se ve con claridad la diferencia sustancial que puede marcar la distinta titularidad que afectaría a algunas de estas estructuras. Ya hemos apuntado que hay torres de titularidad real (entendidas como patrimonio privado de los sultanes), sobre todo localizadas en la Vega y alrededores de Granada. Hemos hablado de ellas, dado que las fuentes son bastante claras, aunque queda aún mucho por dilucidar, en particular acerca de su consideración más como almunias que como torres adscritas a una comunidad rural, a pesar de su ubicación en alquerías. El caso de la Torre de Romilla podría ser emblemático en este sentido.

También las hay adscritas a otros propietarios a título individual, y en consecuencia no parecen presentar un objetivo de servicio a los intereses de la comunidad. El ejemplo que nos ofrece el entorno periurbano de Baza descrito por Alonso de Palencia ${ }^{44}$ y por otro observador directo, Pedro Mártir de Anglería ${ }^{45}$, puede ayudarnos a discernir la especificidad de algunas de estas construcciones. Algo más

\footnotetext{
42. "Los moros que lograron refugiarse en los poblados y en las torres que acostumbran a levantar en los campos avisaron a los suyos con humaredas del desastre sufrido...." Palencia, pp. 418-419.

"...alrededor del 13 de enero ya del año de 1491, habiendo entrado... en el terreno enemigo por la plaza de Montefrío, les robamos en una sola incursión por las alquerías más de tres mil cabezas de cabras, ovejas y bueyes... Los dos observadores, alma de la empresa, se suben a sendos árboles, a los que se les habian añadido más ramas, y al aparecer el sol en el horizonte, desde ellos dan la señal de que las cuadrillas de trabajadores y los pastores con sus ganados se hallan en campo abierto... Asustados huyen los enemigos y se refugian en dos plazas fuertes, defendidas con vallados y torres, todavía inaccesibles para nosostros, que se llaman Hermanas..." Documentos inéditos para la Historia de España, Tomo IX. Epistolario de Pedro Mártir de Angleria, Estudio y traducción por José López de Toro, Madrid, 1953. Libro III, doc. 85, carta al cardenal Arcimboldi, Alcalá la Real, 21 de enero de 1490, pp. 150-151 (En adelante Anglería).

43. "...ciertas reses e dos cristianos maniatados, e fuéronse para la torre diziendo que traían cavalgada, que les abriessen, que no avian donde fuessen por guarescer sino alli. E como los de la torre conoscieron que eran moros, abrieron e saliéronles a recebir...". Bernáldez, cap. XCVI, p. 217.

44. "Todo el que poseía un huerto solía levantar en él una torre y protegerla con tapias para no facilitar a los enemigos de los alrededores el acceso a la ciudad a favor de lo llano del campo", Palencia, p. 400.

"Los de Baza tuvieron que declararse en retirada en dirección a las huertas. Perdieron muchos soldados en la fuga, y no hallaron en las torres el seguro que buscaban porque por los puentecillos echados sobre las acequias y por las mismas callejuelas de los edificios moros y cristianos hallaron camino hasta lo más recóndito, ya en la parte más defendida y próxima a las murallas", Palencia, p. 420.

45. "Por el mediodia, a cerca de nueve estadios, otra vez suaves elevaciones, entre las cuales y la ciudad de Baza se asientan los predios, que llaman huertas, llenas de árboles frutales y de viñedos de uvas para pasas. La superstición mahometana destina estos huertos a un solo uso y los ha dotado de viviendas veraniegas, sin solución de continuidad, en un largo trecho tan unidas, que parecen ser una misma cosa con la ciudad....". Angleria, Libro II, doc. 71, carta al cardenal Arcimboldi, arzobispo de Milán, Baza, 13 de junio de 1489.
} 
tarde también nos lo propone así, de manera clara, Luis del Mármol para la Alpujarra ${ }^{46} \mathrm{y}$ algunas alquerías del valle de Lecrín ${ }^{47}$. Así pueden entenderse también las características constructivas de algunos de estos edificios, levantados con materiales tan frágiles como la madera, tan poco apropiados para proteger la integridad física de personas y bienes frente a eventuales ataques ${ }^{48}$. Aunque en los casos más tardíos se ha llegado a proponer su creación como parte de una estrategia de emulación de la élite morisca frente a la castellana ${ }^{49}$, lo cierto es que el ejemplo ofrecido por el entorno periurbano de Baza, o de la misma Almería ${ }^{50}$ podría llevarnos en otra dirección. Evidentemente, también se trata de una cuestión absolutamente abierta.

En todo caso, las torres que a nosotros nos interesan más son las que están fuertemente vinculadas a grupos, a comunidades campesi- nas, ligadas, de manera más o menos directa, a alquerías o a conjuntos de alquerías ${ }^{51}$, en contacto directo con espacios productivos ${ }^{52}$, y con una capacidad clara de acogida no sólo de personas, circunstancialmente, sino, sobre todo, de bienes ${ }^{53}$, de propiedad tal vez común o en todo caso de tutela común, según se puede desprender de un mantenimiento comunitario vehiculado, quizás, a través de los bienes habíces, según cuanto se puede deducir de algunos testimonios ${ }^{54}$. En todo caso, se trata de indicios aún insuficientes para afirmar este extremo con rotundidad. Es una cuestión compleja de abordar, pero hay que estudiarla, porque a través de su caracterización material puede inferirse su uso comunitario, residencial o de otro tipo. Y en todo caso serían estas últimas las que de manera más estricta se ajustarían a la idea de una estructura ideada para proteger unos bienes cuya propiedad no llegamos a conocer, pero que en todo caso

46. "...hallándose todos [los cristianos] desapercebidos, unos desarmados, y muchos desnudos en camisa, se fueron a meter en la iglesia y en dos torres que tenían en sus casas dos vecinos, que la mayor era de Miguel de Rojas, morisco, y la otra estaba en casa de Pedro López, difunto, escribano mayor que había sido de aquel juzgado”. Ugíjar, Mármol Carvajal, Libro IV, Capítulo XIII.

47. El converso Miguel de Rojas, "...hombre principal del linaje de los Mohayguajes o Carimes, antiguos alguaciles de aquella taa en tiempo de moros...", estaba ofendido con las justicias de Aben Humeya porque "...no le habian dejado acabar una torre fuerte que hacía en su casa; antes se la habían querido derribar...". Mármol Carvajal, Libro IV, Capítulo XXII.

48. "llegaron a casa de Pero López, y entrando por ella, cercaron la torre, que era toda hecha de madera, y poniéndole fuego, quemaron la puente levadiza, y creció la llama tanto, que los de dentro pidieron que se querían dar a partido; y siendo admitidos, mientras descolgaban las mujeres con sogas, que no podían salir por la puerta, que ocupaba el fuego, se quemaron casi todos los hombres, sin poderlos remediar... Mármol Carvajal, Libro IV, Capítulo XV; "En este logar donde el Real se asentó estaba vn alcaría que se llamaua Caçín, con un cortijo e una torre buena, con su cerca gruesa e petril e almenas bien defendederas, e algo del cortijo estaua quemado, quel Rey nuestro Señor lo auia mandado quemar el año pasado. El alquería estaua despoblada, porque por temor de los de Alhama, no labrauan en esta comarca. El qual cortijo e torre mandó su alteza luego al thesorero Ruy López que tomase cargo de lo hazer derribar; e luego en esta misma noche el Thesorero no durmió, andando sobre los peones y dando orden como mas presto se derribase. Lo qual quando amáneselo estaua puesto por el suelo". Alba, p. 34

49. M. Jiménez Puertas, G. García-Contreras Ruiz, L. Mattei, “El fuerte de Lanteira (Granada)...”, p. 208.

50. En la alquería de Pechina, cercana a Almería, Mahoma Moscorrox era dueño de una heredad con dos casas y dos torres. Dolores Segura del Pino, Agua, Tierra y Sociedad en el Río de Almería. De la Época Islámica a la Cristiana (S. XV-XVI), Almería 2000, p. 52.

51. "...dexaron el cerro e descendiéronse a una gran maleza de huertas e viñas que allí estavan, junto con la torre e aldea [de Benalaxar]". Valera, cap. LXIX, p. 211; "E ese día se combatió e derribó la torre de la puente de Pinos (...). En la torre estaban nueve moros, e los quatro mató una lombarda, e los çinco tomaron vibos". Crónica de Juan II, 1431: XVII, p. 497

52. Antonio Malpica ya avanzó algo acerca de esta cuestión en su momento, al aclarar que la función de las torres de alquería podría ser fundamentalmente la defensa de los espacios agrícolas. Antonio Malpica Cuello, Poblamiento y castillos..., p. 133

53. “...alrededor del 13 de enero ya del año de 1491, habiendo entrado... en el terreno enemigo por la plaza de Montefrío, les robamos en una sola incursión por las alquerías más de tres mil cabezas de cabras, ovejas y bueyes... Los dos observadores, alma de la empresa, se suben a sendos árboles, a los que se les habian añadido más ramas, y al aparecer el sol en el horizonte, desde ellos dan la señal de que las cuadrillas de trabajadores y los pastores con sus ganados se hallan en campo abierto...Asustados huyen los enemigos y se refugian en dos plazas fuertes, defendidas con vallados y torres, todavía inaccesibles para nosostros, que se llaman Hermanas". Angleria, Libro III, doc. 85, carta al cardenal Arcimboldi, Alcalá la Real, 21 de enero de 1490, pp. 150-151.

54. Así queda expresado en 1503 en una alusión a los “...bienes habíces de las torres de alquerías...” (Pedro Hernández Benito, La Vega de Granada a fines de la Edad Media según las rentas de los habíces, Granada 1990, p. 113) y así se puede deducir también a partir de la propuesta lanzada por Tendilla en 1515, que transmite la vigencia de una práctica que pudiera proceder de la tradición anterior. "... he pensado que sería bien vna cosa y que pues esto de las penas de la cámara es tan poco y tan mal parado en esta casa, sería bien que pues aquello de los habizes manda que se gaste en las torres, que se diese çédula para que se gastase en las fortalezas que a mi me paresçiese, como dizen que se haga en las torres y cavelle ya su parte al Alhanbra y repararse ya en algunas cosas [y] en otras algunas donde ay gran nesçesidad.... Tendilla, doc. 1630. 
parecen ser objeto de una voluntad clara de preservación de forma comunitaria. Serían éstas las torres a las que podríamos aplicar con más propiedad ese apelativo de "torres de alquerías", no sólo situadas en las alquerías, sino adscritas a las alquerías, pertenecientes de manera estricta a aquellas comunidades residentes en las alquerías.

\section{3 ¿De quién o quiénes se defienden?}

En última instancia, toda construcción de carácter defensivo conlleva otro interrogante: ¿De quién o quiénes se defienden los constructores de estas torres? ¿Ante quién se siente la necesidad de actuar de forma comunitaria? No todas estas fortificaciones están situadas en lugares expuestos, fronterizos o particularmente vulnerables, como la Vega de Granada. Al contrario, zonas de frontera como la región granadina de los Montes, a pesar de contar con una cantidad destacable de alquerías reconocidas en la región, que hablan de un sistema de poblamiento bien organizado, no arrojan un número particularmente elevado de torres de alquería. Precisamente, quizás, la naturaleza estrictamente fronteriza de la zona, facilite el desarrollo aquí más en ningún otro espacio del fenómeno de las villas fortificadas, con los ejemplos de Illora, Iznalloz, Montefrío, Colomera, Píñar, Moclín, Montejícar y Torrecardela ${ }^{55}$. Es decir, que donde se necesita realmente una defensa sólida frente a agresiones exteriores, se suele recurrir a soluciones defensivas de mayor entidad, villas fortificadas o fuertes, y no tanto a estas torres. El Valle de Lecrín, por el contrario, es un ejemplo claro de área más resguardada que sin embargo muestra un alto número de torres de alquería; la Axarquía malagueña y el Altiplano granadino, las hoyas de Baza y Guadix también. Son, todos ellos, ejemplos que ilustran de manera más evidente lo que queremos decir: que la construcción de estos recintos no parece responder a una exigencia defensiva acuciante frente a un peligro que actúa desde el exterior del reino.

Quizás, si seguimos algunos testimonios procedentes de Málaga, se podría deducir que las alquerías también tuvieran que protegerse de comunidades vecinas, e incluso de facciones rivales que intervenían en las luchas civiles que durante el siglo XV asolaron el sultanato. En 1492 se trató en el Consejo Real el pleito que Marina de Villalobos, vecina de Gibraltar, sostenía contra los moros de Casares por el robo de un hato de 500 vacas que tenía pastando en la dehesa del Genal, alquilada a los moros de la villa en 1471. Entre las explicaciones que adujeron éstos, negando ser los autores del robo, figuraba que

\begin{abstract}
era notorio que las dichas vacas habian sido tomadas por gentes poderosas que lo havían venido a haser dende Málaga, los quales avían sido Alí Queçote y los Abençerrajes con mucha gente de cavallo e de pie, e que ellos ni otras más personas que fueran en la dicha villa no los pudieron resistir, quanto más que dixeron que puesto que algunos de la dicha villa oviesen sido en ello, dixeron que la dicha villa estava por los dichos Alí Queçote e Abençerrajes e por el rey moro que ellos tenían alçado con ellos en Málaga contra el rey que que estava a la saçón en la çibdad de Granada, e lo haría por su mandado, aunque no lo osaron ni pudieron resistir. ${ }^{56}$
\end{abstract}

¿Y si el enemigo no procede de fuera? ¿O no se trata exactamente de un enemigo? ¿Y si en realidad no se trata de recintos de defensa? ¿De qué estaríamos hablando entonces?

Preguntas audaces, quizás, prematuras en todo caso, sobre todo teniendo en cuenta que estamos en los primeros estadios de una investigación que debe de ser desarrollada

\footnotetext{
55. Antonio Malpica Cuello, Poblamiento y castillos..., pp. 85 y ss.

56. Archivo General de Simancas, Registro General del Sello, Diciembre 1492, 168, ?-?-1492. El texto se encuentra reproducido íntegramente en José Rodríguez Molina, "Banda territorial común entre Granada y Jaén. Siglo XV”, en Estudios sobre Málaga y el Reino de Granada en el V Centenario de la Conquista, José Enrique López de Coca Castañer (ed.), Málaga 1987, pp. 124-130.
} 
siguiendo la senda desde la que surgió, la del análisis arqueológico.

Lo cierto es que nos encontramos ante un problema histórico de calado, procedente del análisis de la realidad material de los vestigios que nos han llegado de ese pasado, y que por tanto no puede eludir esa responsabilidad de reflexión y conocimiento que pesa sobre ella. Sólo desde la Arqueología llegaremos a entender qué son estas torres de alquería, cuales lo son y cuales no. Hay que darle un significado histórico a estas manifestaciones materiales. Es la Arqueología, la evidencia de vestigios materiales, la que ha llamado la atención en primer lugar sobre una cuestión que presenta un trasfondo histórico profundo y evidente. Y es la Arqueología la que debe de poner orden en ese cajón de sastre, acudiendo a técnicas de análisis arqueológico y a recursos metodológicos tan consolidados como la definición tipológica de las estructuras emergentes. Ya de este modo se percibió por primera vez su complejidad y sólo a través de este recurso seremos capaces de entender realmente la naturaleza y funciones de estas estructuras.

En caso contrario corremos el riesgo de caer en la mera observación estructural y esto, aparte de resultar extraordinariamente limitado en cualquier tipo de conocimiento, resulta que corre el riesgo evidente de, al no ser conocido, quedar malinterpretado.

Sólo cuando a esas descripciones se les ha pretendido ofrecer una interpretación en sistemas de organización de sociedades pasadas, se ha empezado a tomar conciencia de la verdadera complejidad del asunto, del errory confusión cometidos con anterioridad y sobre todo de la enorme potencialidad que muestra su estudio. Sólo entonces se ha comenzado a entender el espacio de reflexión histórica al que se abren desde la Arqueología, situándolas en el corazón mismo del conocimiento de cualquier proceso histórico: la comprensión de las vías y ramificaciones del poder y su capacidad de penetrar en el conjunto de la sociedad dominada. Hablamos, en este caso, de la capacidad del estudio de las llamadas torres del alquería -recuperemos, por qué no, el término convenientemente desbrozado-, para contribuir de manera fundamental al conocimiento de las formas de poder, y de las estrategias de evasión frente a esas formas de dominio, que mantiene la sociedad nazarí. Hablamos, en definitiva, de su capacidad para conocer la historia nazarí.

\section{FUENTES}

Crónica de don Álvaro de Luna, Condestable de Castilla, Maestre de Santiago, edición y estudio por Juan de Mata Carriazo. Madrid 1940.

Crónica de Enrique IV, escrita en latín por Alonso de Palencia, traducción castellana por D. Antonio Paz y Meliá. Madrid 1904.

Crónica de Enrique IV de Diego Enríquez del Castillo. Valladolid 1994.

Crónica de los Reyes Católicos por su secretario Fernando del Pulgar, Ed. Juan de Mata Carriazo. Madrid,1943.

Crónica del halconero de Juan II, Ed. Juan de Mata Carriazo. Madrid, 1946.

Crónicas de los Reyes de Castilla, desde Don Alfonso el Sabio hasta los católicos Don Fernando y Doña Isabel. Madrid, 1953.

Crónica castellana de Enrique IV de Castilla, Ed. crítica y estudio de M. ${ }^{a}$ del Pilar Sánchez-Parra García. Murcia, 1985.

Documentos inéditos para la Historia de España, Tomo IX. Epistolario de Pedro Mártir de Angleria, Estudio y traducción por José López de Toro. Madrid, 1953

Historia de los Hechos del Marqués de Cádiz. Estudio preliminar, edición e índices de Juan Luis Carriazo Rubio. Granada, 2003

Memorial de diversas hazañas: crónica de Enrique IV, ordenada por mosén Diego de Valera, Ed. y estudio por Juan de Mata Carriazo. Madrid 1941.

BERNÁLDEZ Andrés, Memorias del reinado de los Reyes Católicos, edición y estudio por Manuel Gómez-Moreno y Juan de M. Carriazo. Madrid 1962.

MÁRMOL Luis del, Historia de la rebelión y castigo de los moriscos del Reino de Granada. Granada 1997.

MENESES Emilio, Correspondencia del Conde de Tendilla (1508-1513), Madrid 1973; Epistolario del Conde de TendiIla (1504-1506), estudio de José Szmolka Clares; edición y transcripción de M. a Amparo Moreno Trujillo y M.a José Osorio Pérez. Granada 1996.

MORENO Amparo; OSORIO Ma José; DE LA OBRA Juan, Escribiry gobernar: el último registro de correspondencia del Conde de Tendilla (1513-1516). Granada, 2007.

PALENCIA Alonso de, Guerra de Granada, Edición y estudio preliminar R. G. Peinado Santaella. Granada, 1998 
SORIANO Catherine, Los hechos del Condestable don Miguel Lucas de Iranzo: estudio y edición. Madrid 1993

VALERA Mosen Diego de, Crónica de los Reyes Católicos, edición y estudio por Juan de M. Carriazo, Madrid 1927

\section{BIBLIOGRAFÍA}

ACIÉN Manuel (1985), "La fortificación en al-Andalus", Archeologia Medievale XXII, pp. 7-36.

-(1999), Los tugur del Reino Nazarí. Ensayo de identificación", Castrum 5. Archéologie des espaces agraires méditerranéens au Moyen Âge, Murcia, pp. 427-438.

ALMAGRO Antonio (1991), "La torre de Romilla. Una torre nazari en la Vega de Granada”, Al-Qantara, XII, pp. 225-250.

BARCELÓ Miquel (1992), "Saber lo que es un espacio hidráulico y lo que no lo es, o Al-Andalus y los feudales”, J. A. González Alcantud y A. Malpica Cuello, El agua, mitos, ritos y realidades. Granada, 1992, pp. 240-254.

CRESSIER Patrice (1984), "Le chateau et la division territoriale dans l'Alpujarra médiévale: du hisn à la Ta'a”, Melánges de la Casa Velazquez, 20, pp. 115-144.

DÍAZ GARCÍA Isabel (1990), La huerta de Murcia en el siglo XIV: propiedad y producción. Murcia.

FÁBREGAS Adela (en prensa), "Local power agents in the Nasrid kingdom: their influence on social networks and leadership", en Adela Fábregas y Flocel Sabaté (eds.), Power and rural comunities in al-Andalus: ideological and material representations,

FIERRO Isabel (1994), "La legitimidad del poder en el Islam”, Awraq, 15, pp. 147-184.

GUICHARD Pierre (1976), Al-Andalus. Estructura antropológica de una sociedad islámica en Occidente. Barcelona.

- (2000), "Les rapports entre les villes et campagnes", J.C. Garcin et alii, États, societés et cultures du monde musulman medieval. Tome 3. Problemas et perspectivas. Paris, pp. 70-91.

- (2001), Al-Andalus frente a la conquista cristiana: los musulmanes de Valencia (Siglos XI-XIII). Valencia.

-(2009), "El arabismo de los Estados taifas", A. Malpica, R. Peinado, A. Fábregas (eds.), Actas del VII Coloquio de Historia de Andalucía. Qué es Andalucía. Una revisión histórica desde el Medievalismo. Granada, vol. I, pp. 47-57.

GUICHARD Pierre; BAZZANA André (1978), "Les tours de défense de la huerta de Valence au XIIIe siècle", Mélanges de la Casa de Velázquez, 14 , pp. 73-105.

JIMÉNEZ Miguel (2002), "Asentamientos rurales y frontera: las torres de alquería de la tierra de Loja en época nazarí", C. Trillo San José, Asentamientos rurales y territorio en el Mediterráneo medieval. Granada, pp. 390-421.

JIMÉNEZ Miguel, GARCÍA-CONTRERAS Guillermo, MATTE Luca (2010), "El fuerte de Lanteira (Granada). Análisis de una fortificación de alquería en época nazari", Arqueología de la Arquitectura, 7, pp. 191-211.
LÓPEZ ELUM Pedro (2002), Los castillos valencianos en la Edad Media (materiales y técnicas constructivas). Valencia.

MALPICA Antonio (1996), Poblamiento y castillos en Granada. Barcelona.

-(1996), "La alquería nazarí de Bordonar en la Vega de Granada", Estudios de historia y arqueología medievales, IX, pp. 313-348.

-(1998), "Los castillos en época nazarí. Una primera aproximación”, Castillos y territorio en al-Andalus. Granada, pp. 246-293.

-(2003), Los castillos en Al-Andalus y la organización del territorio. Cáceres.

MARTÍN Mariano (2000), "Torres de alquería de la provincia de Granada", Actas del Tercer Congreso Nacional de Historia de la Construcción. Sevilla, pp. 651-664.

- (2010) "Torres de alquería de la Vega de Granada”, PH. Boletín del Instituto Andaluz de Patrimonio Histórico, 74, pp. 46-54.

MARTÍNEZ ENAMORADO Virgilio (2006), "Lema de príncipes". Sobre la galiba y algunas evidencias epigráficas de su uso fuera del ámbito nazarí", Al Qantara, XXVII, pp. 529-550.

- (2006), Torrox. Un sistema de alquerías andalusies en el siglo XV según su Libro de Repartimiento. Granada.

- (2008), Cuando Marbella era una tierra de alquerías: sobre la ciudad andalusí de Marballa y sus alfoces. Marbella.

MOLINA Emilio (2000), "La dinámica política y los fundamentos del poder”, R. Peinado Santaella(ed.), Historia del Reino de Granada. I: De los orígenes a la época mudéjar. Granada, pp. 211-248.

REYES Luis (1986), "Técnicas de construcción de las fortificaciones en el reino de Granada”, Actas del II Simposio Internacional del mudejarismo. Teruel, pp. 373-388.

RODRÍGUEZ MOLINA José (1987), "Banda territorial común entre Granada y Jaén. Siglo XV”, Estudios sobre Málaga y el Reino de Granada en el V Centenario de la Conquista. Málaga, pp. 124-130.

RODRÍGUEZ NAVARRO P. (2008), La torre árabe observatorio en tierras valencianas. Tipología arquitectónica. Valencia, tesis doctoral (http://dspace.upv.es/xmlui/ handle/10251/3542)

SEGURA DEL PINO Dolores (2000), Agua, Tierra y Sociedad en el Río de Almería. De la Época Islámica a la Cristiana (S. XV-XVI). Almería.

TORRES BALBÁS Leopoldo (1953), "La torre de Gabia (Granada)". Al-Andalus XVIII , pp. 187-198.

- (1956), "La torre de Gabia la mayor, desmochada", AlAndalus XXI, pp. 375-377.

TORRÓ Josep (1998), "Fortificaciones en Yibal Balansiya. Una propuesta de secuencia”, A. Malpica Cuello (ed.), Castillos y territorio en Al-Andalus..., pp. 385-418. 